\title{
The AuScope Geochemistry Laboratory Network
}

\author{
BRENT I.A. MCINNES ${ }^{1 *}$, ANDREW GLEADOW ${ }^{2}$ AND \\ SUZANNE Y. O'REILLY ${ }^{3}$
}

${ }^{1}$ John de Laeter Centre, Curtin University, Bentley, WA 6102 Australia (*b.mcinnes@curtin.edu.au)

${ }^{2}$ School of Earth Sciences, University of Melbourne, VIC 3010 Australia (gleadow@unimelb.edu.au)

${ }^{3}$ GEMOC, Dept of Earth \& Planetary Sciences, Macquarie

University, NSW 2109 Australia (sue.oreilly@mq.edu.au)

In 2019, AuScope commissioned a project that would establish a national collaborative network of geochemistry laboratories, with the mission to: (i) promote existing geochemical capability across the nation; (ii) promote capital and operational investments in new, advanced geochemical infrastructure; (iii) develop a central repository for multiple isotopic data sets; (iv) support Australian participation in national and international open data initiatives; (v) support professional development via online tools, training courses and workshops; and (vi) support increased end user access to laboratory facilities.

An AuScope Geochemical Network (AGN) Project Office has been established at Curtin University to initiate and develop the network. Project activities will initially focus on the development of a data repository in the form of an Isotopic Atlas eResearch Platform. The platform will initially host major data collections held at Curtin (SHRIMP U-Pb), Macquarie (Hf isotopes) and Melbourne (Fission-track/U$\mathrm{He})$.

There are plans to expand the activity to include additional datasets from other institutions wishing to collaborate within the AGN framework.

A secondary benefit of the project is that it will also allow individual researchers to upload geochemical datasets related to their publications, a requirement of many leading academic journals.

It is anticipated that, over time, this new repository will aggregate a large volume of publicly funded geochemical data, and will be a key resource useful in quantitatively understanding Earth system processes that have shaped the formation and evolution of the Australian continent and its resources. 